\title{
"HOJE VAI TER PARQUINHO?": EXPERIÊNCIAS E REGISTROS DE UMA EXTENSÃO UNIVERSITÁRIA NA EDUCAÇÃO INFANTIL
}

\section{"WILL THERE BE PLAYGROUND TODAY?": THE EXPERIENCES AND RECORDS OF A UNIVERSITY EXTENSION ACTIVITY ON EARLY CHILDHOOD EDUCATION}

\author{
Cláudia Mara Niquini* \\ ORCID: https://orcid.org/0000-0003-4583-0107 \\ Priscila Lopes** \\ ORCID: https://orcid.org/0000-0002-1896-1841 \\ Juliana Nogueira Pontes Nobre*** \\ ORCID: https://orcid.org/0000-0002-9876-1136 \\ Sandro Vinicius Sales dos Santos**** \\ ORCID: https://orcid.org/0000-0002-9666-3639
}

\section{Resumo}

O presente texto relata experiências de uma extensão universitária desenvolvida por um curso de licenciatura em Educação Física (EF) de uma universidade pública, em um Centro Municipal de Educação Infantil (CMEI) vinculado à rede municipal de ensino de uma cidade de Minas Gerais. Para tanto, utilizamos diferentes registros: relatórios das ações de extensão, registros do cotidiano do projeto e narrativas de docentes e discentes da universidade e do referido CMEI. A partir disto, organizamos nossa exposição em três eixos: cotidiano do projeto; atividades formativas desenvolvidas com os profissionais do CMEI; atividades desenvolvidas com as crianças. Consideramos que o projeto de extensão e seus desdobramentos contribuíram para a formação dos licenciandos em EF, para a rotina institucional e para a formação continuada dos profissionais do CMEI no campo da cultura corporal, enriquecendo as experiências corporais partilhadas por crianças e adultos no ambiente da educação infantil.

Palavras-chave: Educação infantil; Extensão; Cultura corporal.

\begin{abstract}
This study presents the experiences of a university extension activity developed by students of Physical Education (PE) course from a public university, in a Municipal Center of Early Childhood Education (CMEI, Brazilian abbreviation) linked to a network of teaching in a city of Minas Gerais. We carried it out through reports of the extension actions, registers of the daily activities and from narratives provided by teachers and students of the university and CMEI. Thus, we organized our study considering three core points: the daily project activities; the formative activities developed with the professionals from CMEI; the activities developed with the children. We understand that the extension project and its outcomes contributed to the formation of the PE graduates, to the institutional routine and to the continuing education of the professionals from CMEI in the field of body culture, enriching the body experiences shared by children and adults in the early childhood education environment.
\end{abstract}

Keywords: Early childhood education; Extension; Body culture.

Data recebimento: 02/02/2021

Data de aceite: 07/05/2021
* Professora da Universidade Federal dos Vales do Jequitinhonha e Mucuri (UFVJM), Diamantina, MG - Brasil. E-mail: claudia.niquini@ufvjm.edu.br

** Professora da Universidade Federal dos Vales do Jequitinhonha e Mucuri (UFVJM), Diamantina, MG-Brasil.E-mail: priscila.lopes@ufvjm.edu.br

*** Aluna de Doutorado da Universidade Federal dos Vales do Jequitinhonha e Mucuri (UFVJM), Diamantina, MG - Brasil. E-mail: junobre2007@yahoo.com.br

**** Professor da Universidade Federal dos Vales do Jequitinhonha e Mucuri (UFVJM), Diamantina, MG - Brasil. E-mail: sandro.santos@ufvjm.edu.br 


\section{Introdução}

Este relato apresenta resultados de um projeto de extensão universitária que, dentre outros objetivos, articulou docentes e estudantes de um curso de licenciatura em Educação Física (EF) e profissionais e crianças de um Centro Municipal de Educação Infantil (CMEI) de uma específica cidade mineira. Em nosso entendimento, as articulações entre o ensino superior e instituições educativas, além de importantes, são vitais para a formação qualificada de futuros professores e diminuem a distância entre esses dois níveis de ensino, mobilizando o fortalecimento de ambos os segmentos (DOURADO, 2015).

Neste conjunto, ressaltamos as ações de extensão no seio universitário como possibilidade de transformações sociais importantes na sociedade, sobretudo, na valorização da educação pública. Acreditamos que o desenvolvimento de pesquisas em educação, articuladas a projetos de extensão, pode contribuir para a superação de práticas pedagógicas dissonantes, tornando menor a distância comumente observada entre a pesquisa e a prática educativa, isto é, entre a universidade e a escola de educação básica (GOMES, 2009; FORPROEX, 2012; MARTINS; DIAS; MARTINS FILHO, 2016).

Defendemos uma extensão universitária desenvolvida por meio de um processo educativo, científico, interdisciplinar, dialógico, crítico, reflexivo e emancipatório. Evidenciamos, ainda, dois aspectos de suma importância para a realização de ações de extensão: a dialogicidade, no sentido de promover relações entre a universidade e diferentes setores sociais por meio do diálogo e troca de saberes; o impacto e transformação social - tanto na sociedade quanto na universidade - que imprime à extensão um caráter essencialmente político (ALMEIDA, 2015; BENINCÁ; CAMPOS, 2017; FREIRE, 1985; FORPROEX, 2012).

Em que pesem essas considerações, a extensão universitária torna-se condição sine qua non para o avanço dos processos formativos de profissionais de educação infantil (EI), dado que a primeira etapa da educação básica concentra o maior percentual de profissionais sem habilitação em nível superior (OLIVEIRA; VIEIRA, 2010). Em pesquisa que objetivou compreender a condição docente na educação básica brasileira, essas autoras identificam que, apesar desse quadro, as profissionais de EI, no conjunto de profissionais da educação básica, são as que mais apontam para a formação continuada e em serviço como uma das principais estratégias de melhoria da qualidade do atendimento de bebês e crianças pequenas em creches e pré-escolas (OLIVEIRA; VIEIRA, 2010).

Nesse sentido, o objetivo do presente trabalho é descrever processos e práticas pedagógicas relativas à cultural corporal de movimento $(\mathrm{CCM})$, caras à formação de licenciandos/as da $\mathrm{EF}$, desenvolvidas em uma instituição educativa, por meio de um projeto extensionista de uma universidade pública de Minas Gerais. A partir desse objetivo, buscaremos refletir sobre potencialidades e limitações da aproximação universidade-escola básica, verificando contribuições do campo da $\mathrm{EF}$, em especial àquelas relativas ao brincar e demais elementos da CCM na rotina de crianças e adultos, estabelecendo, desse modo, processos de formação continuada de professores da EI. 
Soares et al. (2012, p. 18) definem que a EF é um componente curricular que "trata, pedagogicamente, na escola, do conhecimento de uma área denominada de cultura corporal", que abrange os conteúdos da ginástica, jogos, esportes, lutas, dança e outros. González e Fensterseifer (2009) ainda salientam que a EF, ao ser integrada a proposta pedagógica de estabelecimentos educacionais, passa a ter obrigações que se relacionam ao papel da instituição na qual está inserida, que é o de construir conhecimentos que possam subsidiar a formação crítica e autônoma do indivíduo.

Consideramos, entretanto, que tal conceituação deve ser cuidadosamente interpretada para o contexto da EI, já que a estrutura curricular de creches e pré-escolas, apesar de figurar em uma proposta de nucleação de uma Base Nacional Comum para a educação básica, pressupõe a centralidade da criança e de suas experiências nas propostas pedagógicas dessas instituições (SANTOS, 2018). Assim, se por um lado tivemos a preocupação de não veicular a EF como componente curricular a ser trabalhado junto às crianças, o processo formativo foi organizado de modo a sensibilizar as profissionais do CMEI para as possibilidades de ampliação da brincadeira e demais manifestações da CCM de meninos e meninas.

Logo, com o intuito de tratar e favorecer a CCM de crianças na EI, no ano de 2018, nasceu o projeto de extensão "Pipocando na Educação Infantil", proposto por docentes do departamento de EF da Universidade Federal dos Vales do Jequitinhonha e Mucuri (UFVJM) no CMEI Bom Jesus (CMEI-Bom Jesus), na cidade de Diamantina, Minas Gerais.

Entre distintas ações, o projeto previu a construção de um "parquinho" para brincar na escola com brinquedos feitos de materiais recicláveis (pneus e outros) que possibilitassem às crianças o "se-movimentar", de forma espontânea ou dirigida (LOPES; NOBRE; NIQUINI, 2020), isto é, por meio de experiências intencionalmente planejadas pelas profissionais da escola.

Segundo Kunz (1991), o "se-movimentar" humano enfoca o sujeito do movimento e não o movimento do sujeito, ressaltando que as experiências com o corpo se diferenciam das situações de aprendizagem sobre o corpo, considerando o sentido e o sentimento sobre as diferentes possibilidades do corpo em que vivemos.

No intuito de favorecer a compreensão do projeto, apresentaremos, conforme figuras a seguir, algumas passagens da construção do parquinho, lócus privilegiado das ações do projeto em pauta. 
Figura 1 - Fase inicial - Parque de Pneus - Projeto Pipocando na EI

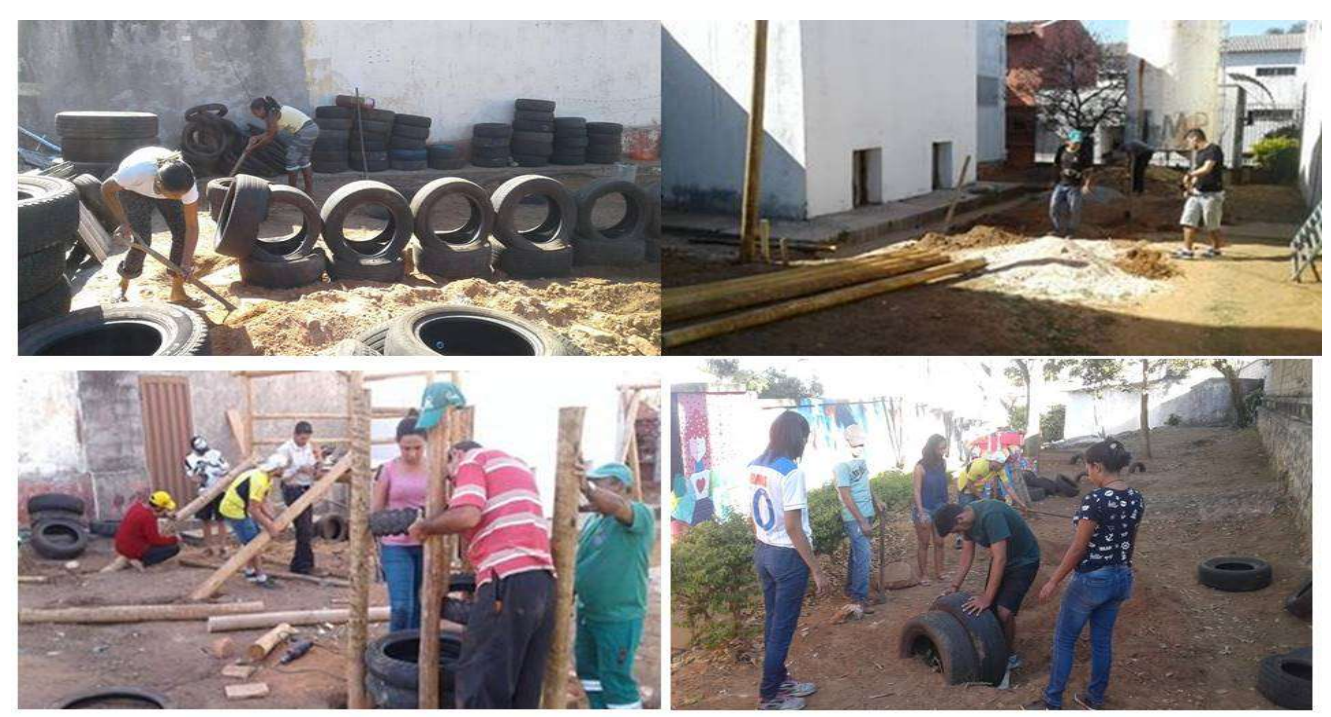

Fonte: Relatórios de extensão - Pipocando/UFVJM, ano 2018.

Dentre as distintas atividades desenvolvidas em favor da construção do parque, destacamos o envolvimento da comunidade escolar, no qual pais, gestores e professores abraçaram a ideia e empenharam-se na edificação de um novo local para a escola (LOPES; NOBRE; NIQUINI, 2020).

Levando em consideração as imagens apresentadas anteriormente e a Figura 2, a seguir, podemos destacar a importância das modificações realizadas neste espaço, favorecendo o lúdico e a abertura de "um novo mundo" para "o mundo" das crianças, onde elas puderam interagir e aprender brincando, valorizando a ludicidade e o tempo para brincar. 
Figura 2 - Fase final: Parque de Pneus - Projeto Pipocando na EI
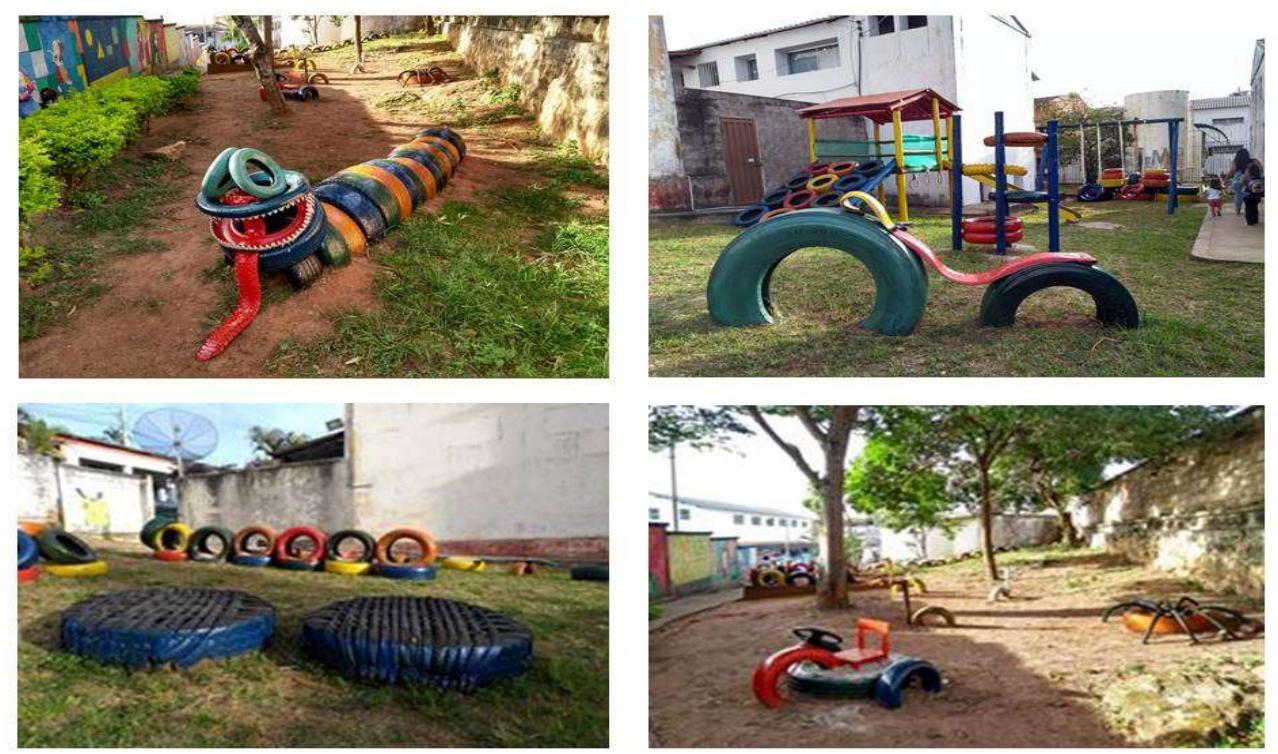

Fonte: Relatórios de extensão- Pipocando/UFVJM, ano 2018.

Em 2019, com uma nova proposta, o projeto de extensão ampliou seus objetivos, propondo experiências no parque construído e a realização de oficinas de formação continuada para o corpo docente da escolaii.

Neste relato, optamos em compreender e discorrer sobre o desenvolvimento dos trabalhos realizados a partir dos registros recolhidos pela universidade (documentos exigidos pela Pró reitoria de extensão e cultura (PROEXC) para acompanhamento e finalização do projeto) e dos relatos dos sujeitos envolvidos.

De acordo com os materiais levantados e as narrativas de distintos sujeitos (monitores, professores da EI e coordenadores do projeto), elencamos algumas questões que moveram nossos interesses e auxiliaram na produção deste relato de experiência: Como ocorreu o projeto de extensão na relação universidade e instituição educativa? Quais as contribuições do específico projeto de extensão para os profissionais da escola? Quais as contribuições do projeto para as crianças?

Assim, para melhor desenvolvimento deste relato, optamos por organizá-lo em quatro eixos discursivos: 1. Educação, CMEI, conhecimentos da EF: articulações necessárias; 2. Percursos e registros; 3. Apresentação e discussão dos dados; 4. Considerações finais. 


\section{Educação, CMEI, conhecimentos da EF: articulações necessárias}

Desde a década de 1980, a EI vem construindo referências no campo educacional que, dentre outros fatores, reconhecem creches e pré-escolas como direito das crianças e de suas famílias, bem como um dever do Estado. A legislação educacional brasileira incorporou as instituições de EI aos sistemas de ensino, tal como previsto na Lei de Diretrizes e Bases da Educação Nacional - LDB (BRASIL, 1996), mas que já era algo celebrado pela Carta Constituição da República de 1988 e que inaugurou uma nova doutrina jurídica da infância, compreendendo, desde então, as crianças como cidadãs de direitos (BRASIL, 1988).

Desse ponto de vista, a política de EI que começa a ser implantada em nosso país, a partir da década de 1990, reclama uma organização curricular que, concomitantemente, atenda às exigências legais impostas pela legislação educacional, ao passo em que respeite as especificidades etárias das crianças de até seis anos de idade (BARBOSA; RITCHER, 2015) - processo que inclui o brincar e demais formas de interação das crianças, e sobretudo outras manifestações corporais de meninos e meninas.

Demarcando distintas modificações e compreensões sobre as práticas corporais ao longo da história, destacamos que, no século XIX, ganhou espaço o discurso da educação do corpo para alcançar comportamentos e posturas corretas perante a sociedade. A partir dessa concepção de corpo novo, surgem, então, os exercícios para a movimentação corporal, ora no sentido de promover o corpo forte e saudável, ora no desejo de estabelecer os desígnios da sociedade vigente. Nesse conjunto, ressaltamos o fortalecimento da instituição escolar, alinhada a esse discurso pernicioso de corpo "forte, saudável e eficiente" (SOARES, 2012, p. 17). Compreendemos que tais práticas corporais, ao longo dos séculos XIX e XX, quando inseridas no processo educativo, objetivaram o disciplinamento dos corpos, com efeitos visíveis até hoje nas práticas escolares, inclusive, nas instituições de EI.

Entendemos o ambiente escolar como "lugar de circular, de reinventar, de estimular, de transmitir, de produzir, de usufruir, enfim, de praticar cultura" (VAGO, 2009, p. 34). Esse lugar possui especificidades na sua organização e nas culturas que serão compartilhadas e produzidas pelos indivíduos que fazem parte desse contexto. A EF faz parte desse ambiente e participa do processo levando em consideração a sua particularidade (VAGO, 2009).

A EF tem como objetivo formar sujeitos críticos e reflexivos acerca do meio em que vivem/vivência, componente curricular este que integramos os alunos no universo da cultura corporal de movimento:

[...] a EF escolar, na condição de disciplina, tem como finalidade formar indivíduos dotados de capacidade crítica em condições de agir autonomamente na esfera da cultura corporal de movimento e auxiliar na formação de sujeitos políticos, munindo-os de ferramentas que auxiliem no exercício da cidadania (GONZÁLEZ; FENSTERSEIFER, 2009, p. 12). 
Através de aulas e atividades desenvolvidas com as crianças, a EF deve propor, de forma crítica e reflexiva, experiências da cultura em que este sujeito vive e das possibilidades que dispõe este espaço, enriquecendo as vivências das crianças e os contributos desta área de conhecimento para a formação continuada de profissionais de EI, como forma de aproximação, reconhecimento e ampliação das experiências corporais das crianças.

Interessa-nos demarcar que a EI está inserida na educação básica e é ofertado em espaços específicos para a educação das crianças. De acordo com Basei (2008, p.01), é, portanto, "um lugar de descobertas e de ampliação das experiências individuais, culturais, sociais e educativas, através da inserção da criança em ambientes distintos dos da família".

Entendemos ser um espaço e um tempo em que sejam integrados o desenvolvimento da criança, seu mundo de vida, sua subjetividade, com os contextos sociais e culturais que a envolvem através das inúmeras experiências que ela deve ter a oportunidade e estimulo de vivenciar nesse espaço de sua formação.

Segundo Soares et al. (2012), a EF, enquanto componente curricular, trata o amplo universo da cultura corporal, no qual a movimentação do corpo e as possibilidades do "semovimentar" ganham importância e ampliam as possibilidades das experiências individuais e coletivas dos escolares. De acordo com a LDB, em seu artigo 26, parágrafo $3^{\circ}$, "A Educação Física, integrada à proposta pedagógica da escola, é componente curricular obrigatório da educação básica" (BRASIL, 1996).

Ayoub (2001) cita que, na EI, a EF é tratada no eixo movimento e, na maioria das vezes, seu desenvolvimento é realizado por professores generalistas que atuam nas diversas áreas do conhecimento, sendo abordada como "movimento livre" ou como "o apenas brincar" (p. 54). No entanto, a autora demarca as contribuições da EF para este nível de ensino e defende que a criança deve ser o ponto central e primário de possíveis intervenções, pensando "num currículo que contemple diferentes linguagens em suas múltiplas formas de expressão, as quais se manifestam por meio da oralidade, gestualidade, leitura, escrita, musicalidade..." (AYOUB, 2001, p. 55).

Corroboramos o pensamento de autores que acreditam que, apesar de sua especificidade e importância para a educação de crianças, os conhecimentos provenientes da EF ainda são pouco trabalhados no cotidiano da EI (AYOUB, 2001; BONFIETTI et al., 2019; OLIVEIRA; LOPES; NOBRE, 2019; PINHO; GRUNENNVALDT; GELAMO, 2016). Interessa-nos, sobremaneira, defender a importância de uma maior presença de conhecimentos oriundos da EF na formação (inicial e continuada) de profissionais de EI, ampliando as capacidades sobre as ideias, os movimentos, as palavras, as experiências, entre outros.

Esses conhecimentos devem ser tratados ao longo da formação das crianças, favorecendo uma educação ampliada, dando destaque às culturas locais e às identidades brasileiras, além de proporcionar descobertas de movimentos, conhecimento do corpo, percepção de lugar onde interagem socialmente e culturalmente, valorizando as experiências corporais para uma formação enriquecida de conhecimento. 
[...] Além disso, é um espaço para que, através de situações de experiências - com o corpo, com materiais e de interação social - as crianças descubram os próprios limites, enfrentem desafios, conheçam e valorizem o próprio corpo, relacionem-se com outras pessoas, percebam a origem do movimento, expressem sentimentos, utilizando a linguagem corporal, localizem-se no espaço, entre outras situações voltadas ao desenvolvimento de suas capacidades intelectuais e afetivas, numa atuação consciente e crítica (BASEI, 2008, p. 1).

O "se-movimentar" da criança possibilita a ela o conhecimento do corpo, de suas espontaneidades, seus limites e de expressarem seus sentimentos, construindo assim, sua identidade. O corpo cria uma forma de comunicação com outros sujeitos, possibilitando, na primeira infância, novas descobertas e criações com atividades lúdicas que envolvam gestos e movimentos corporais.

\section{Percursos e registros}

Trata-se de um relato de experiência por meio do qual descreveremos uma ação extensionista, no intento de contribuir para a formação continuada e em serviço de profissionais da EI, tendo como eixo central as brincadeiras e práticas corporais das crianças e dos adultos, com destaque aos conhecimentos oriundos da EF.

O projeto de extensão "Pipocando na Educação Infantil: movimento(s) e ludicidade", foco de atenção e relato, foi desenvolvido pelo departamento de EF da UFVJM de 2018 a 2020, e contou com a produção de diferentes documentos, a saber: relatórios parciais (elaborados semestralmente), relatórios finais, relatórios parciais e finais de bolsistas de extensão e trabalhos acadêmicos desenvolvidos a partir das experiências no projeto ${ }^{\text {iii }}$.

Os dados apresentados neste trabalho foram gerados pelos registros supracitados e pelos relatos de diferentes participantes do projeto: docentes e discentes da UFVJM; docentes, crianças e gestão do CMEI-Bom Jesus, definindo três eixos de exposição: cotidiano do projeto; atividades formativas desenvolvidas com profissionais da escola; atividades desenvolvidas com crianças e adultos.

Importante registrar que, no período do projeto, o CMEI-Bom Jesus atendia aproximadamente 220 crianças, entre 6 meses e 5 anos de idade, e optou-se em trabalhar com as turmas acima de 3 anos, somando-se, ao todo, 11 turmas com aproximadamente 16 crianças.

Considerando nossos propósitos, elaboramos o Quadro 1, o qual evidencia questões norteadoras que deram origem à produção deste relato. 
Quadro 1 - Questões geradoras do relato de experiência

\begin{tabular}{|c|c|}
\hline Questões norteadoras & Tema decorrente \\
\hline $\begin{array}{c}\text { Como ocorreu o projeto de extensão na relação universidade e } \\
\text { instituição educativa? }\end{array}$ & $\begin{array}{c}\text { Articulações entre universidade e o } \\
\text { CMEI }\end{array}$ \\
\hline $\begin{array}{c}\text { Quais as contribuições do projeto para os profissionais da } \\
\text { escola? }\end{array}$ & $\begin{array}{c}\text { Formação continuada de professores } \\
\text { da EI }\end{array}$ \\
\hline Quais as contribuições da EF para as crianças? & O corpo e o movimento na EI \\
\hline
\end{tabular}

Fonte: Elaborado pelos autores.

\section{Apresentação e discussão dos dados}

\section{Articulações entre universidade e o CMEI}

O planejamento do projeto foi desenvolvido de forma processual e dialógica, priorizando a constante comunicação entre os membros da universidade e da escola, como sugere a literatura sobre o desenvolvimento de ações extensionistas (CRUZ; VASCONCELOS, 2017; FREIRE, 1985; FORPROEX, 2012; GADOTTI, 2017).

A partir de demandas levantadas pela direção da escola e de informações coletadas em um questionário diagnóstico aplicado às profissionais da EI da CMEI-Bom Jesus, a equipe de planejamento - formada por três docentes e cinco licenciandos em EF (um monitor bolsista e quatro monitores voluntários) do Departamento de EF da UFVJM - estruturou um cronograma de ações para serem desenvolvidas no decorrer do ano de 2019, contendo atividades voltadas para a formação continuada do quadro docente do CMEI-Bom Jesus e atividades direcionadas às crianças.

Verificamos, portanto, que a estruturação da ação extensionista emergiu das necessidades e potencialidades presentes na comunidade educativa da instituição. Os conhecimentos prévios das profissionais e os âmbitos sociais em que eles se desenvolveram foram levados em consideração e, ao invés de impor a substituição de formas de agir, buscou-se promover a problematização, o diálogo com a vivência de mundo da comunidade, fazendo com que as pessoas envolvidas desenvolvessem uma nova forma de atuar por meio da conscientização (FREIRE, 1985).

As ações voltadas para a formação continuada do quadro docente escolar ocorreram mensalmente, com datas estabelecidas de acordo com o calendário fornecido pela direção do CMEI-Bom Jesus. Foram desenvolvidas oficinas com temáticas sugeridas pelo corpo docente, com duas horas de duração, em forma de palestras ou intervenções práticas, ministradas por colaboradores do projeto e acompanhadas pela bolsista de extensão, em diferentes espaços da universidade e da escola. 
As atividades direcionadas às crianças foram planejadas em um encontro semanal, envolvendo docentes e discentes da UFVJM, com o objetivo de estudar referências necessárias para o desenvolvimento da EF na EI, compartilhar ideias para criação de atividades e avaliar aquelas que já haviam sido realizadas, no sentido de ponderar as dificuldades encontradas.

Cada monitor realizou dois encontros semanais, em turmas estabelecidas por eles em reunião de planejamento, envolvendo, de forma obrigatória, a profissional responsável pela turma. As aulas tinham uma hora de duração para cada sala da EI, sendo o primeiro encontro da semana em atividades realizadas no parque de pneus da escola, e o segundo, em algum espaço livre da instituição (quadra, espaço do refeitório ou brinquedoteca).

No segundo semestre de 2019, três discentes da UFVJM concluíram a graduação, exigindo uma modificação em parte da dinâmica do projeto. Diante disso, o desenvolvimento das atividades com as crianças passou a ser realizado de forma conjunta entre os dois discentes restantes e as profissionais responsáveis pela turma. Em cada um dos dois dias da semana, eram atendidas diversas turmas, com atividades realizadas no parque de pneus ou no espaço livre da escola. Nesse período, não foi possível manter a regularidade de dois encontros por semana, para cada turma.

Diante do exposto, percebemos que a formação dos licenciandos foi contínua durante a ação extensionista, permitindo o protagonismo dos mesmos frente às aulas, a partir de reflexões sobre suas experiências em campo e a relação com o conhecimento desenvolvido dentro da universidade (ensino e pesquisa). Da mesma forma, verificamos a constante troca de saberes por meio da interação dos membros da universidade com os da comunidade do CMEI-Bom Jesus, ambos "aprendizes" e "ensinantes", presentes durante o desenvolvimento das experiências com as crianças e as formações com as profissionais.

\section{Formação continuada de professores $\mathrm{da} E I$}

Durante o projeto, as formações continuadas ocorreram uma vez por mês, nos encontros de módulos temáticos preestabelecidos pela escola, por meio dos quais foram realizadas as oficinas e palestras do projeto.

A finalidade desta formação foi de ampliar o repertório teórico-metodológico das profissionais do CMEI-Bom Jesus, promovendo seu desenvolvimento enquanto docentes que atuam em creches e pré-escolas, ampliando o repertório relativo à cultura corporal, estendendo, desse modo, a qualidade das experiências ofertadas às crianças (AMADOR, 2019).

Neste sentido, notamos a participação significativa das profissionais da EI nos momentos de formação continuada. Apesar da delicadeza enfrentada pelas docentes no que toca à sobrecarga de trabalho, a resistência à exposição corporal e vivências de experiências corporais, o projeto propôs, ao longo dos encontros, a sensibilização dos sentidos e dos movimentos, identificando, nas trocas de experiências, uma mistura de sentimentos: euforia, prazer, alegria, medo, entusiasmo, enfim, um (re)conhecimento do/no corpo de caminhos para as crianças. 
Nesse contexto, Tardif (2002) considera que o transcurso de aprender e ensinar se aviva antes mesmo da formação inicial do docente, ao qual acrescentamos que se inicia na própria história de vida pessoal de cada professor. Os conteúdos ali aprendidos pelas profissionais pretendiam sanar algumas dúvidas e dificuldades apontadas por elas.

O Quadro 2, a seguir, ilustra os temas desenvolvidos em cada oficina, os quais agregaram diferentes olhares, experiências e saberes.

Quadro 2 - Oficinas de formação continuada.

\begin{tabular}{|c|cl|}
\hline Mês/2019 & \multicolumn{2}{l|}{ Temáticas } \\
\hline Abril & 1. & Ginástica para todos \\
\hline Maio & 2. & A criança e o currículo da EI \\
\hline Junho & 3. & Comportamentos na infância \\
\hline Julho & 4. & $\begin{array}{l}\text { A dança na formação continuada de professoras da EI: possibilidades para a educação } \\
\text { estética }\end{array}$ \\
\hline Agosto & 5. & A dança na EI: limites e possibilidades \\
\hline Setembro & 6. & A importância do brincar no desenvolvimento da criança \\
\hline Outubro & 7. & Educação Inclusiva \\
\hline Novembro & 8. & Pipocando na EI: um relato das articulações entre ensino, pesquisa e extensão \\
\hline
\end{tabular}

Fonte: Elaborado pelos autores.

As oficinas foram ministradas por docentes da universidade de diferentes áreas do conhecimento, atendendo diretrizes do FORPROEX (2012), que sugerem a superação da dicotomia entre a visão holística e a visão especializada, por meio da interação de modelos, conceitos e metodologias de disciplinas e áreas do conhecimento diversas.

$\mathrm{Na}$ oficina 1, realizada no Laboratório de Ginástica do Campus Jk da UFVJM, as profissionais tiveram a oportunidade de vivenciar os elementos da ginástica, observando as grandes possibilidades que podem ser trabalhadas na escola. Foram desenvolvidas estações nos equipamentos dispostos no espaço, permitindo vivências corporais diversas, tais como: saltos, aterrissagens, rotações, balanços, equilíbrios, apoios, suspensões e manejo de materiais (RUSSEL, 2010; TOLEDO; TSUKAMOTO; CARBINATTO, 2016).

Desenvolvida no espaço da escola, a oficina 2 buscou tratar sobre a Base Nacional Comum Curricular (BNCC). Para tanto, foram apresentadas as possibilidades de construção de um currículo a partir das experiências das crianças, demonstrando-se às profissionais as especificidades do currículo e sua produção, seguido de um momento para dialogar sobre dúvidas referentes a BNCC e as Diretrizes Curriculares Nacionais da Educação Infantil (DCNEI) (BRASIL, 2010). 
A oficina 3, também no espaço da escola, abordou questões relativas às crianças apontadas pelas profissionais no cotidiano da escola, tais como: agressividade, dificuldades de se relacionar, obedecer a regras, relações familiares, entre outras; além de estratégias possíveis para fortalecer o vínculo com os diversos membros da comunidade escolar.

As oficinas 4 e 5 foram desenvolvidas em um espaço cultural do Campus I da UFVJM, com o objetivo de proporcionar experiências individuais e coletivas no que tange a dança. As atividades contempladas compreenderam os tempos, a música, os deslocamentos, a pausa e o movimento, além da produção de uma pequena composição coreográfica ao final das oficinas. As vivências tocaram a sensibilidade das profissionais para a temática em questão, pois, além de abranger elementos da dança, foram proporcionadas experiências que interagiram com outros elementos, tais como a utilização de materiais alternativos, produção de sons com o próprio corpo, etc., estimulando a criatividade para trabalhar com as crianças em suas práticas pedagógicas.

As três últimas oficinas foram realizadas nas dependências do CMEI-Bom Jesus. A oficina 6 , cuja temática envolveu a importância do brincar, em que a colaboradora trouxe elementos pertinentes sobre a construção do aprender pelo brincar e vice-versa. Por meio de distintas dinâmicas, a discussão valorizou o brincar das profissionais e suas histórias cotidianas sobre o tema, ressaltando, entre diferentes falas, o quanto o "brincar" torna o aprendizado prazeroso para o entendimento de regras, para a construção de valores e para a apropriação da cultura humana.

A oficina 7 foi desenvolvida por meio de diálogos sobre o tema inclusão no dia a dia da escola, no qual os desafios e as possibilidades de atividades inclusivas foram abordados. No intuito de conscientizar sobre as dificuldades enfrentadas pelas pessoas com deficiências, a dinâmica do encontro contou com experimentações corporais semelhantes àquelas que pessoas com deficiência vivem no cotidiano escolar, permitindo um valioso debate sobre atividades rotineiras que permitiriam o acesso e boas vivências de escolares com deficiências.

A oficina 8, com presença de todos os envolvidos no projeto (profissionais da escola, monitora do projeto e docentes da UFVJM), teve como intuito realizar uma síntese de todas as atividades realizadas pela ação extensionista. Constituiu-se em um momento de escuta, diálogo e troca de experiências, avalição (oral e escrita), além do fechamento do projeto, contemplando os agradecimentos aos envolvidos. 
A seguir, apresentamos imagens de algumas atividades realizadas durante a formação continuada.

Figura 3 - Formação continuada - projeto Pipocando na EI
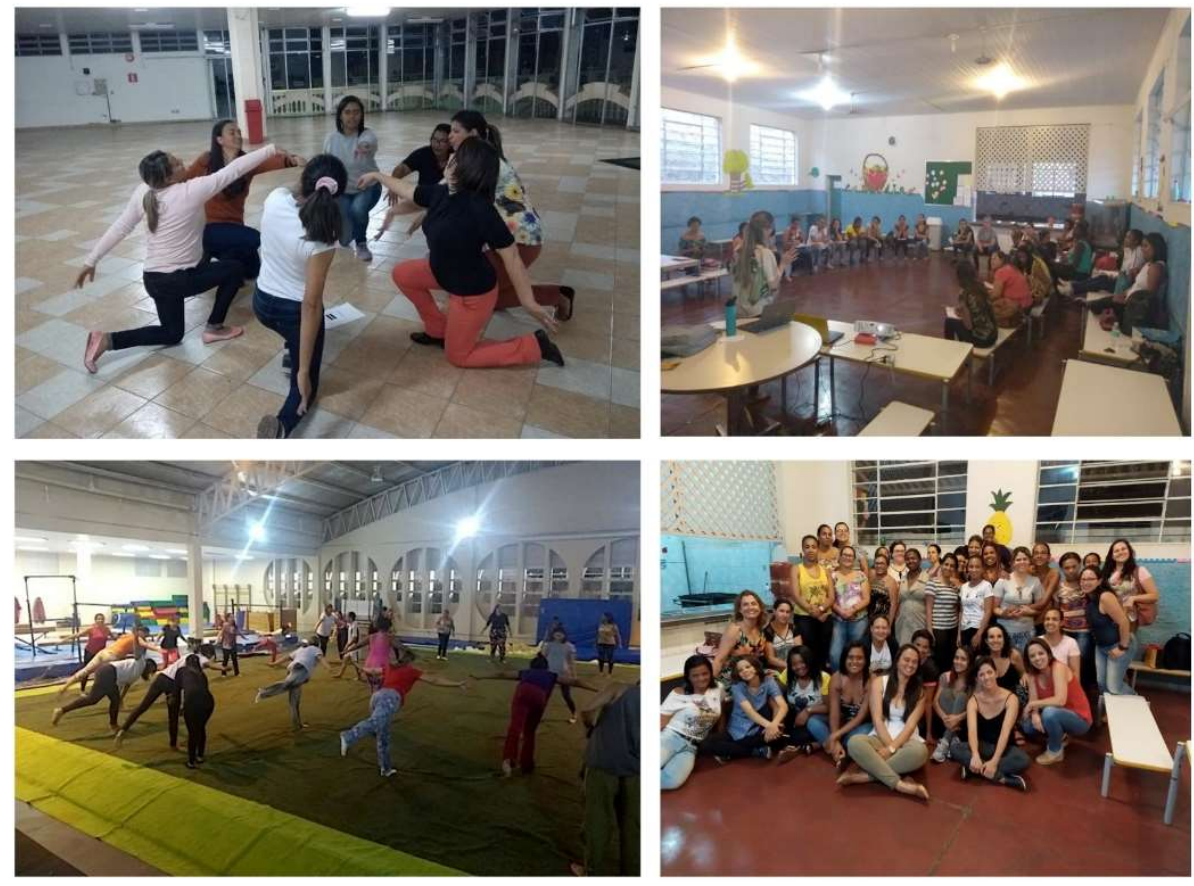

Fonte: Relatórios de extensão - Pipocando na EI/UFVJM, ano 2019

Complementando os registros do projeto, destacamos algumas reflexões presentes no trabalho de conclusão de curso (TCC) da bolsista de extensão, trazendo à baila aspectos que destacaram para a estudante na formação continuada de professores, a saber: 1. Vivência/ experiência da cultura corporal de movimento, favorecendo a experimentação e o trabalho coletivo, no concreto da escola; 2. O trabalho em conjunto de professoras, educadoras e colaboradores do projeto favoreceu a confiança mútua e o (re)conhecimento das práticas corporais como recurso para as aulas na escola, despertando o desejo por novas práticas pedagógicas; 3 . A receptividade das crianças frente às brincadeiras e afins tornou as professoras satisfeitas com suas aulas e interações; 4. A carência de "cuidados" às professoras da EI foi perceptível, pois, nos relatos das professoras, elas destacaram a oportunidade de partilharem suas experiências e viverem sua corporeidade.

Da mesma forma, algumas dificuldades devem ser registradas: cansaço das professoras no momento de formação, uma vez que a maior parte das docentes trabalha dois turnos, em escolas distintas; resistência de professoras em participarem de atividades com as crianças, uma vez que o projeto na escola é visto como "folga/descanso" para as mesmas; receio de 
usarem os espaços "de brincar" construídos na escola na ausência do projeto, com a preocupação de sujar e/ou machucar as crianças.

\section{O corpo e o movimento na EI}

As DCNEI nos dizem que as práticas pedagógicas devem ocorrer de modo a não fragmentar a criança nas suas possibilidades de viver experiências, na sua compreensão do mundo feita pela totalidade de seus sentidos.

Segundo Ayoub (2001), movimentando-se, a criança se descobre, descobre o outro, descobre o mundo à sua volta e suas múltiplas linguagens. O movimento atrelado a situações lúdicas possibilita à criança brincar com a linguagem corporal, o que significa ocasionar momentos nos quais ela se relaciona com diferentes manifestações da cultura corporal desenvolvidas pelos seres humanos ao longo da história, nos mais diversos contextos socioculturais.

O Quadro 3, a seguir, sintetiza as intervenções propostas pelos bolsistas de extensão no projeto, ao longo do ano de 2019 , tendo como referência o planejamento das aulas. As aulas, em cada turma, ocorreram duas vezes por semana, com duração de 50 minutos, tanto no ambiente do parque de pneus como no espaço do refeitório ou quadra.

Quadro 3 - Experiências sensoriais, expressivas e corporais.

\begin{tabular}{|c|l|}
\hline Mês/2019 & \multicolumn{1}{|c|}{ Atividades norteadoras desenvolvidas com os escolares } \\
\hline Abril & $\begin{array}{l}\text { Tempo de brincar no parque (sem orientação) / } \\
\text { Movimentos gímnicos (com orientação) }\end{array}$ \\
\hline Maio & $\begin{array}{l}\text { Tempo de brincar no parque (sem orientação) / } \\
\text { Gestos e musicalidade (com orientação) }\end{array}$ \\
\hline Junho & $\begin{array}{l}\text { Tempo de brincar no parque (sem orientação) / } \\
\text { Jogos no parque de pneus (com orientação) }\end{array}$ \\
\hline Julho & $\begin{array}{l}\text { Tempo de brincar no parque (sem orientação) / } \\
\text { Capoeira e brinquedos cantados (com orientação) }\end{array}$ \\
\hline Agosto & $\begin{array}{l}\text { Tempo de brincar no parque (sem orientação) / } \\
\text { Danças e expressões rítmicas (com orientação) }\end{array}$ \\
\hline Setembro & $\begin{array}{l}\text { Tempo de brincar no parque (sem orientação) / } \\
\text { Contações de estórias(com orientação) }\end{array}$ \\
\hline Outubro & $\begin{array}{l}\text { Tempo de brincar no parque (sem orientação) / } \\
\text { Jogos com bolas e arcos (com orientação) }\end{array}$ \\
\hline Novembro & $\begin{array}{l}\text { Tempo de brincar no parque (sem orientação) / } \\
\text { Jogos com cordas e jornal (com orientação) }\end{array}$ \\
\hline
\end{tabular}

Fonte: Elaborado pelos autores. 
Como já relatado, destacamos que o propósito do projeto era utilizar de maneira frequente o espaço do parque de pneus. Neste sentido, toda semana, com a presença da monitora bolsista de extensão, as crianças brincavam no parquinho. Denominado como "tempo de brincar no parque sem orientação", apesar da mediação da monitora, as crianças podiam livremente escolher o que desejavam fazer no espaço.

Após esse momento, os monitores propunham atividades orientadas distintas, seguindo as decisões do planejamento, a saber: movimentos gímnicos; gestos e musicalidade; jogos no parque de pneus; capoeira e brinquedos cantados; danças e expressões rítmicas; contações de estórias; jogos com bolas e arcos; jogos com cordas e jornal.

Figura 4 - Atividades com as crianças - projeto Pipocando na EI
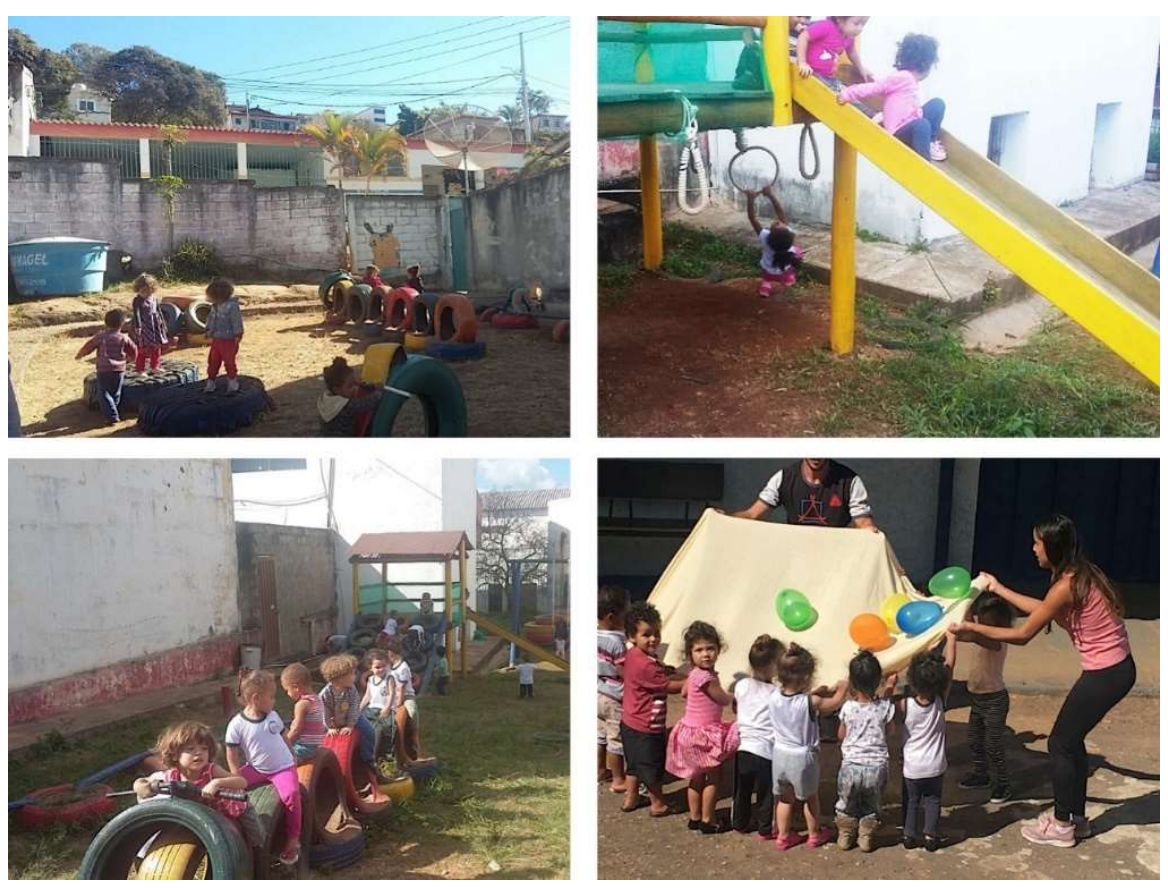

Fonte: Relatórios de extensão - Pipocando na EI/UFVJM, ano 2019.

Registramos que essas proposições foram mutáveis e flexíveis, em acordo com o interesse e o envolvimento das crianças. Contudo, a organização permitiu um repertório de atividades interessantes a serem desenvolvidas com as crianças, possibilitando diversificar tempos, espaços, materiais, ritmos, habilidades, interações, contatos, enfim, enriquecendo a infância e o tempo na/da escola.

A partir dos registros analisados, identificaram-se diferentes elementos da cultura corporal no desenvolvimento do projeto, como ginástica, dança, capoeira, jogos, entre outros, proporcionando às crianças o acesso a esse rico universo, estimulando o brincar e o tempo destinando às experiências que atravessam o corpo. 
Também destacamos o estímulo à participação das profissionais da EI no momento destas intervenções, favorecendo a sensibilização sobre as práticas desenvolvidas, a troca de saberes e a articulação de conteúdos ministrados em sala no ambiente externo, ampliando o repertório de práticas pedagógicas possíveis (e necessárias) no ambiente da EI.

Para Lopes et al. (2015), independentemente do nível de ensino, a EF deve extrapolar a proposta de se restringir apenas às atividades que circunscrevem sua área de atuação, desenvolvendo trabalhos na escola de forma interdisciplinar, o que poderia facilitar o aprendizado do aluno sobre o mundo, uma vez que a própria vida não se apresenta de forma compartimentalizada e fragmentada.

Por fim, ressaltamos que o projeto se preocupou em garantir a vivência das crianças no parque e para a brincadeira, por meio do qual os monitores interagiam a partir do movimento espontâneo da criança, escutando seu desejo e sua imaginação e, sobremaneira, aprendendo com eles. Outro ponto a considerar se refere à insegurança das profissionais em usar o parque com receio de a criança cair, machucar, sujar, entre outros. Foi algo evidente essa resistência do uso de espaços com "pouco controle", deixando claras as limitações impostas às crianças.

\section{Considerações finais}

O presente relato versou sobre a importância do movimento e do brincar para a vida da criança na escola infantil a partir de uma experiência extensionista. Entendemos ser de suma importância as relações entre ensino superior e instituições educativas, permitindo aproximações, aprendizagens e trato pedagógico de temas (e conteúdo) importantes para as crianças em desenvolvimento.

O projeto "Pipocando na Educação Infantil: movimento(s) e ludicidade" evidenciou a força e a importância da articulação de saberes (universidade e EI) em prol de uma educação pública qualificada para futuros cidadãos.

Consideramos que o projeto de extensão em destaque e seus desdobramentos contribuíram para a melhoria da qualidade do ambiente escolar, para a formação continuada do professor da EI e para propostas pedagógicas qualificadas no campo da cultura corporal na EI. Da mesma forma, colaboraram para a formação dos membros da universidade a partir da interação com a realidade vivida no chão da escola e da troca de saberes com a sociedade, destacando, sobremaneira, o trato e a disseminação da cultura corporal para as novas gerações.

Por fim, partindo do entendimento de que a educação deve ser plural e demarcando a importância do brincar, acreditamos que as maiores contribuições do projeto ainda não poderão ser descritas, haja vista que as crianças, essência do projeto, não foram ouvidas de forma qualificada. Todavia, acreditando na beleza da infância, nas trocas experenciadas, na riqueza dos aprendizados, nos sorrisos, na alegria, nos olhos cheios de expectativas, a melhor frase sempre foi: "sim, sim, sim, hoje tem parquinho!". 


\section{Referências}

ALMEIDA, Luciane Pinho. A extensão universitária no Brasil: processos de aprendizagem a partir da experiência e do sentido. DIRE [En ligne], n. 7, 2015, Disponível em: http://epublications.unilim.fr/revues/dire/692. Acesso em: 30 abr. 2018.

AMADOR, Judenilson Teixeira. Concepções e modelos da formação continuada de professores: um estudo teórico. Revista Humanidades e Inovação, v.6, n. 2, p. 151-167, 2019.

AYOUB, Eliana. Reflexões sobre a educação física na educação infantil. Revista Paulista de educação física, São Paulo, s/n, supl.4, p. 53-60, 2001.

BONFIETTI, Priscila Errerias; SPOLAOR, Gabriel da Costa; GRILLO, Rogério de Melo; PRODÓCIMO, Elaine. O/a professor/a de educação física na educação infantil. Revista @mbienteeducação, São Paulo, v. 12, n. 1, p. 160-176, jan./abr. 2019.

\section{BRASIL. [Constituição (1988)]. Constituição da República Federativa do Brasil de} 1988. Brasília, DF: Presidência da República, [2016]. Disponível em: http://www.planalto.gov.br/ccivil_03/Constituicao/Constituiçao.htm. Acesso em: 1 jan. 2017.

BRASIL, MEC; CNE, CEB. Diretrizes curriculares nacionais para a educação infantil. Resolução CEB-CNE, v. 1, 2010.

BRASIL. Lei de Diretrizes e Bases da Educação Nacional. Brasília, DF: Senado Federal, p.1-62, 2018. Disponível em:

https://www2.senado.leg.br/bdsf/bitstream/handle/id/544283/lei_de_diretrizes_e_bases_2ed.pdf.

BASEI, Andréia Paula. A Educação Física na Educação Infantil: a importância do movimentar-se e suas contribuições no desenvolvimento da criança. Revista

Iberoamericana de Educación, Centro de Educação da Universidade Federal de Santa Maria, n. 47/3, p. 1-12, 25 out. 2008.

BARBOSA, Maria Carmen Silveira; RITCHER, Sandra Regina Simonis. Campos de Experiência: uma possibilidade para interrogar o currículo. In: FINCO, Daniela; BARBOSA, Maria Carmen Silveira; FARIA, Ana Lucia Goulart de (Eds.). Campos de experiências na escola da infância: contribuições italianas para inventar um currículo de Educação Infantil brasileiro. Campinas: Edições Leitura Crítica. 2015. p. 185-198. 
BENINCÁ, Dirceu; CAMPOS, Fernando Silva. Extensão Popular: uma proposta transformadora para a educação superior. Dialogia, n. 27, p. 145-156, set./dez. 2017. Disponível em: http://periodicos.uninove.br/index.php?journal=dialogia\&page $=$ article\&op=view\&path $\% 5 B$ $\% 5 \mathrm{D}=7247 \&$ path $\% 5 \mathrm{~B} \% 5 \mathrm{D}=3617$. Acesso em: 30 abr. 2018.

CRUZ, Pedro José Santos Carneiro; VASCONCELOS, Eymard Mourão. Caminhos da aprendizagem na extensão universitária: reflexões com base na experiência na articulação nacional de extensão popular. São Paulo: HUCITEC Editora, 2017.

DOURADO, Luís Fernando. Diretrizes Curriculares Nacionais para a formação inicial e continuada dos profissionais do magistério da educação básica: concepções e desafios. Educação e Sociedade, Campinas, v. 36, n. 131, p. 299-324, abr.jun. 2015.

FORPROEX. Política Nacional de Extensão Universitária. Manaus. 2012. Disponível em: https://www.ufmg.br/proex/renex/documentos/2012-07-13-Politica-Nacional-deExtensao.pdf. Acesso em: 10 ago. 2016.

FREIRE, P. Extensão ou comunicação? 8. ed. Rio de Janeiro: Paz e Terra, 1985. Disponível em: http://www.emater.tche.br/site/arquivos_pdf/teses/Livro_P_Freire_Extensao_ou_Comunica cao.pdf . Acesso em: 30 abr. 2018.

GADOTTI, Moacir. Extensão Universitária: Para quê? 17 fev. 2017. Disponível em: https://www.paulofreire.org/noticias/557-extensao-universitaria-para-que. Acesso em: 28 maio 2018.

GOMES, Marineide de Oliveira O. Formação de professores na educação infantil. São Paulo: Cortez, 2009.

GONZÁLEZ, Fernando Jaime; FENSTERSEIFER, Paulo Evaldo. Entre o "não mais" e o "ainda não": pensando saídas do "não-lugar da EFE I. Cadernos de Formação RBCE, v.1, n.1, p. 9-24, 2009.

KUNZ. Elenor. Educação física: ensino e mudanças. Ijuí: Unijuí, 1991.

LOPES, Priscila; LEAL, Juliana; VALIENGO, Amanda; GONÇALVES, Edvânia; GOMES, Nayara; PESSOA, Taynara. Ginástica Para Todos e literatura: realidade, possibilidades e criação. Conexões, Campinas, v. 13, n. Especial, p. 127-146, maio 2015. 
LOPES, Priscila; NOBRE, Juliana Nogueira; NIQUINI, Cláudia Mara. Parque na escola: uso (s) de materiais alternativos e ações coletivas para a Educação infantil. Revista Educação Popular, Uberlândia, v.19, n.2, p.214-227, maio/ago. 2020.

MARTINS, Rosa Elisabete Militz Wypyczynski; DIAS, Julice; MARTINS FILHO, Lourival José. O contexto do ensino, pesquisa e extensão na formação docente na Faculdade de Educação da Universidade do Estado de Santa Catarina. Revista de Educação PUCCampinas, v. 21, n. 2, p. 243-254, 2016.

OLIVEIRA, D. A. de.; VIEIRA, L. M. F. Trabalho docente na educação básica no Brasil. Belo Horizonte: GESTRADO/UFMG, 2010, 80 p. (Relatório de pesquisa).

OLIVEIRA, Z. M. R. O currículo na Educação Infantil: $O$ que propõem as novas diretrizes nacionais? Brasília, DF, 2010. Disponível em: http://portal.mec.gov.br. Acesso em: 8 maio 2020 .

OLIVEIRA, Michelly Tatiane; LOPES, Priscila; NOBRE, Juliana Nogueira Pontes. Ginástica na Educação Infantil: uma análise das publicações do Fórum Internacional de Ginástica Para Todos. Conexões, Campinas, v. 17, p. 1-19, 2019.

PINHO, Vilma Aparecida; GRUNENNVALDT, José Tarcísio; GELAMO, Kátia Garcia. O lugar da educação física na educação infantil, existe? Motrivivência, v. 28, n. 48, p. 222 240, set. 2016.

RUSSEL, Keith; NUNOMURA, Myrian. Uma alternativa de abordagem da ginástica na escola. Revista UEM, Maringá, v. 13, n. 1, p. 123-127, 2002.

SANTOS, Sandro Vinicius Sales dos. Currículo da educação infantil - considerações a partir das experiências das crianças. Educação em REvista [online], 2018, v.34, e188125. Disponível em: http://www.scielo.br/scielo.php?script=sci_arttext\&pid=S010246982018000100149\&lng=en\&nrm=iso. Acesso em: set. 2020.

SOARES, Carmen Lúcia et al. Metodologia do Ensino da Educação Física (Coletivo de Autores). São Paulo: Cortez, 2012.

TARDIF, M. Saberes docentes e formação profissional. Petrópolis: Vozes, 2002.

TOLEDO, E.; TSUKAMOTO, M. H. C.; CARBINATTO, M. V. Fundamentos da Ginástica Para Todos. In: NUNOMURA, M. (Org.) Fundamentos das ginásticas. 2. ed. Várzea Paulista: Fontoura, 2016. 
VAGO, Tarcísio Mauro. Pensar a educação física na escola: para uma formação cultural da infância e da juventude. Cadernos de Formação RBCE, p. 25-42, set. 2009.

VIEIRA, L. M. F. O perfil das professoras e educadoras da Educação Infantil no Brasil. Docência na Educação Infantil. Salto para o Futuro, ano XXIII, jun. 2013.

\footnotetext{
Notas

${ }^{\text {i }}$ De acordo com Vieira (2013, p.19), a pesquisa possibilitou compreender que “[...] no âmbito da educação básica, a educação infantil concentra os professores mais jovens, mulheres, não brancas e com menor escolaridade. [...] Nessa etapa da educação básica concentram-se as maiores frequências dos que trabalham em uma única unidade educacional e que cumprem mais longas jornadas de trabalho diárias em uma mesma unidade. É nela que são encontradas as maiores frequências dos que auferem remuneração mais baixa, na faixa de 1 a 2 salários mínimos mensais, em relação aos docentes das outras etapas da educação básica, cruzando-se as variáveis: formação, vínculo de trabalho e jornada semanal.

ii O projeto foi submetido e aprovado pelo Edital 01/2019 do Programa Institucional de Bolsas de Extensão da Pró-reitora de Extensão e Cultura (PROEXC) da UFVJM, o que viabilizou apoio financeiro para implementação da proposta e a presença de bolsista de extensão remunerado.

iii Respeitando-se questões éticas, o projeto foi registrado na PROEXC da UFVJM (n³16644.1753.312106.19112018) e aprovado pelo Comitê de Ética em Pesquisa da UFVJM (parecer 2.850.668).
} 